\title{
Effects of Atrial Natriuretic Peptide on Glycerol Induced Acute Renal Failure in the Rat
}

\author{
George Seki, M.D., Keiji Suzuki, M.D., Tatsuya Nonaka, M.D., \\ Kazuo Nosaka, M.D., Shigeo Taniguchi, M.D., \\ Chikara Aızawa, M.D., and Kiyoshi Kurokawa, M.D.
}

\begin{abstract}
Summary
Acute and chronic experiments were performed in rats to examine whether atrial natriuretic peptide (ANP) has any bencficial effects on glycerol-induced acute renal failure (ARF). ANP infusion (Atriopeptin III, $1.0 \mu \mathrm{g} / \mathrm{kg}+0.2 \mu \mathrm{g} / \mathrm{kg} / \mathrm{min}$ ) improved the renal blood flow (RBF) and the glomerular filtration rate (GFR), and induced profound natriuresis in the early stage of ARF. By contrast, ANP decreased RBF in the control rats. In addition to these acute hemodynamic effects, long-term beneficial effects of ANP were also observed. A 75-min infusion of ANP significantly lessened the degree of azotemia as well as the extent of renal histologic damage assessed 24 hours after the glycerol injection. These results indicate that ANP can afford partial protection against both acute renal dysfunction and the chronic course of the glycerol-induced ARF, suggesting that ANP may be useful in the treatment of ARF.
\end{abstract}

\section{Key Words:}

Glycerol-induced ARF ANP GFR RBF Natriuresis

Histological injuries

\begin{abstract}
A
LTHOUGH the syndrome of acute renal failure (ARF) has been studied for many years, the prognosis of this syndrome is still very poor. Diuretics such as furosemide and some vasodilators have been tried as therapeutic agents in a number of studies, but results have not been consistent. ${ }^{1{ }^{-5)}}$ Recent animal studies have shown that atrial natriuretic peptide (ANP) can correct acute renal dysfunction in the ischemic ARF model. ${ }^{63-9)}$ However it is still unclear whether ANP has any beneficial effects in other experimental models of ARF. We have evaluated the effects of ANP in glycerol-induced ARF in the rat because this model shows many features with human ARF. ${ }^{10), 11)}$ Acute experiments were performed to examine the acute

From the First Department of Internal Medicine, Faculty of Medicine, University of Tokyo, Tokyo, Japan.

Mailing address: George Seki, M.D., First Department of Internal Medicine, Faculty of Medicine, University of Tokyo, Hongo 7-3-1, Bunkyo-ku, Tokyo 113.

Received for publication October 24, 1991 .

Accepted January 9, 1992.
\end{abstract}


hemodynamic effects of ANP in the early stage of renal failure. Next, chronic experiments including the renal histological studies, were performed to clarify the long-term effects of ANP infusion on the chronic course of ARF.

\section{Methods}

The study was performed on male Sprague-Dawley rats weighing from 278 to $359 \mathrm{~g}$. All animals were maintained on a standard diet and allowed free access to water until 24 hours before the injection of glycerol or saline, when water was withheld. They lost about $7 \%$ of their body weight during this dehydration period. Two series of experiments were done.

\section{Acute experiments :}

In 7 rats, 50\% glycerol was injected intramuscularly into the bilateral hindlimbs at a total dose of $10 \mathrm{ml} / \mathrm{kg}$ (Group 1). In 9 rats saline was injected instead of glycerol (Group 2). Approximately $45 \mathrm{~min}$ after the glycerol or saline injection rats were anesthetized with Inactin $(100-130 \mathrm{mg} / \mathrm{kg}$ i.p., Byk Gulden Konstanz, FRG). Body temperature was maintained at $36.5-37.5^{\circ} \mathrm{C}$ and a tracheostomy was performed. The left and right jugular veins were cannulated for infusion of saline, inulin, or ANP. The right carotid artery was also cannulated for blood sampling and measurement of blood pressure (BP) using a pressure transducer (Nihon Kohden, Tokyo). The urinary bladder was catheterized through a suprapubic incision, and the urethra was ligated. A left flank incision was made and a flow probe $(0.5 \mathrm{~mm}$ I.D.) was placed on the left renal artery, and renal blood flow was measured continuously using an electromagnetic flow meter (Nihon Kohden). Zero calibration of the flow metcr was done at the end of each experiment by occluding the renal artery distal to the flow probe. At the completion of the surgical preparation, a saline dose equivalent to $1 \%$ of body weight was infused into the left jugular vein at $0.8 \mathrm{ml} / \mathrm{min}$ in order to replace surgical blood loss and the infusion was maintained thereafter at $0.08 \mathrm{ml} / \mathrm{min}$. An infusion of $3 \%$ inulin in saline was also started simultaneously at $0.02 \mathrm{ml} / \mathrm{min}$ into the right jugular vein. A 20-min control clearance period followed an equilibration period of $80 \mathrm{~min}$. This control period was centered 3 to 3.5 hours after the glycerol or saline injection. Subsequently synthetic ANP (Atriopeptin III, Peninsula Laboratories, USA) was administered through the left jugular vein; $1.0 \mu \mathrm{g} / \mathrm{kg}$ in $0.2 \mathrm{ml}$ saline was given as a priming dose, followed by a $30 \mathrm{~min}$ constant infusion at a rate of $0.2 \mu \mathrm{g} / \mathrm{kg} / \mathrm{min}$. Fifteen min after the initiation of the ANP infusion a 15-min experimental clearance was obtained. A 20-min recovery clearance was then made $30 \mathrm{~min}$ after the discontinuation of the ANP 
infusion. In the middle of each clearance period a $200 \mu l$ sample of blood was taken from the carotid artery for chemical analysis. The appropriate constant infusion rate was maintained constant throughout the clearance periods.

\section{Chronic experiments :}

After being dehydrated for 24 hours as in the acute experiment, rats were anesthetized with pentobarbital $(40 \mathrm{mg} / \mathrm{kg}$ i.p.) supplemented with ether and a catheter was placed in the right femoral vein. Blood $(300 \mu \mathrm{I})$ was then drawn from the tail artery for the determination of control values of blood urea nitrogen (BUN) and plasma creatinine. Prior to the glycerol injection a rapid saline infusion equivalent to $1 \%$ of body weight was delivered at $0.4 \mathrm{ml} / \mathrm{min}$ through the catheter. The same rapid saline infusion was repeated $75 \mathrm{~min}$ after the injection of $50 \%$ glycerol $(10 \mathrm{ml} / \mathrm{kg} \mathrm{i.m.)} \mathrm{in} \mathrm{order} \mathrm{to} \mathrm{par-}$ tially replace a large volume deficit. The animals were then divided into Group 3 and Group 4. The saline infusion was continued for $75 \mathrm{~min}$ at $0.08 \mathrm{ml} / \mathrm{min}$ in Group $3(\mathrm{~N}=13)$ following the second rapid saline infusion. In Group $4(\mathrm{~N}=12)$, AP III was added to the saline and infused at $0.2 \mu \mathrm{g} /$ $\min$ for $75 \mathrm{~min}$. At the end of these infusions the catheter was removed and the femoral vein was ligated. After awakening from anesthesia the rats were placed in individual metabolic cages, and their urine volume and water intake were recorded. Twenty-four hours after the glycerol injection, the rats were anesthetized with ether and through a midline abdominal incision blood was obtained from the aorta for measurements of hematocrit ( $\mathrm{Ht}), \mathrm{BUN}$, and plasma creatinine.

\section{Histologic studies:}

Prior to the blood sampling from the aorta, the left renal pedicle was ligated and the left kidney was removed promptly. Sagittal sections were obtained from the kidney, immersion-fixed in buffered formaline and processed for microscopy. Hematoxylin-and-eosin stained sections were examined by one of the authors (K.N.) without any knowledge concerning the treatments. $\Lambda$ fter examining more than 50 highpower fields, histological injuries were scored for two factors:

1) The degree of necrosis in the $S_{1}$ and the $S_{2}$ segments of the proximal tubule (Grade 0 to 3 ). Grade 3 was assigned to those with the most severe necrosis, defined as greater than $60 \%$ of the observed tubules involved.

2) The extent of cast formation in the outer medulla (Grade 0 to 3 ). Grade 3 was assigned to those with most extensive changes, defined as on average more than 15 tubules involved per field $(\times 100)$. 


\section{Analytical procedures:}

GFR was estimated by inulin clearance and inulin concentrations were determined by the anthrone method. BUN was measured by the UREA-N test (Wako Junyaku, Japan), and plasma creatinine by Creatinine-Analyzer 2 (Beckman, USA). Sodium concentrations in plasma and urine were determined using a flame photometer (Corning, USA), and urine volume (UV) was measured gravimetrically.

\section{Statistics:}

Statistical analysis was performed by paired t test with Bonferroni's adjustment within groups. Student's t-test or Wilcoxon's non-parametric procedure was used to identify differences between groups. Correlations in the histologic study were determined using Kendall's rank test. Data are expressed as mean values $\pm \mathrm{SE}$, and a $p$ value of $<0.05$ was considered significant.

\section{Results}

\section{Acute experiments :}

The acute hemodynamic effects of ANP from the control rats and the rats with early-stage renal failure are summarized in Table I. During the control period, the group receiving the glycerol injection (Group 1) showed

Table I. Effects of ANP on Systemic and Renal Parameters in Acute Experiments

\begin{tabular}{|c|c|c|c|c|c|}
\hline & & & Control Period & Experimental Period & Recovery Period \\
\hline \multirow[t]{2}{*}{$\mathrm{BP}$} & $(\mathrm{mmHg})$ & G1 & $147.3 \pm 2.8$ & $128.7 \pm 4.2^{*}$, & $140.1 \pm 4.0 *$ \# \\
\hline & & $\mathrm{G} 2$ & $133.9 \pm 2.9$ & $112.1 \pm 2.7^{*}$ & $123.9 \pm 3.5^{*}$ \\
\hline \multirow[t]{2}{*}{$\mathrm{Ht}$} & $(\%)$ & G1 & $48.4 \pm 1.2$ & $49.8 \pm 1.4 *$ & $47.4 \pm 1.5$ \\
\hline & & $\mathrm{G} 2$ & $47.7 \pm 0.8$ & $49.6 \pm 0.9^{*}$ & $46.3 \pm 1.0$ \\
\hline \multirow[t]{2}{*}{ RBF } & $(\mathrm{ml} / \mathrm{min})$ & G1 & $2.87 \pm 0.42 \#$ & $4.20 \pm 0.63^{*}, \#$ & $2.80 \pm 0.50 \#$ \\
\hline & & $\mathrm{G} 2$ & $6.43 \pm 0.19$ & $5.77 \pm 0.21^{*}$ & $7.10 \pm 0.29 *$ \\
\hline \multirow[t]{2}{*}{ GFR } & $(\mathrm{ml} / \mathrm{min})$ & G1 & $0.05 \pm 0.02 \#$ & $0.22 \pm 0.05^{*}, \#$ & $0.08 \pm 0.03^{*}$ \\
\hline & & $\mathrm{G} 2$ & $2.42 \pm 0.14$ & $2.93 \pm 0.09 *$ & $2.52 \pm 0.15$ \\
\hline \multirow[t]{2}{*}{ UV } & $(\mu 1 / \min )$ & G1 & $3.25 \pm 1.07 \#$ & $51.84 \pm 8.39 *$ & $10.33 \pm 2.41^{*}$ \\
\hline & & $\mathrm{G} 2$ & $6.60 \pm 0.40$ & $39.74 \pm 10.41^{*}$ & $7.99 \pm 0.42^{*}$ \\
\hline \multirow[t]{2}{*}{ UNaV } & ( & GI & $0.09 \pm 0.03 \#$ & $6.05 \pm 0.85^{*}$ & $0.93 \pm 0.30^{*}$ \\
\hline & & $\mathrm{G}^{2}$ & $0.34 \pm 0.05$ & $8.34 \pm 2.60^{*}$ & $0.99 \pm 0.14^{*}$ \\
\hline \multirow[t]{2}{*}{ FENa } & $(\%)$ & Gl & $4.04+2.01 \#$ & $25.95 \pm 5.80 *$,\# & $12.50 \pm 5.27 \#$ \\
\hline & & $\mathrm{G} 2$ & $0.10 \pm 0.02$ & $1.92 \pm 0.59 *$ & $0.28 \pm 0.05^{*}$ \\
\hline
\end{tabular}

Data: mean \pm SEM. $B P=$ mean blood pressure; $\mathbf{G l}=$ Group 1 (ARF group, N=7); G2=Group 2 (control group, $\mathrm{N}=9$ ). * $\mathrm{P}<0.05$ vs control period, \# $\mathrm{p}<0.05$ vs Group 2 . 
significant increases in mean $\mathrm{BP}$ and fractional sodium excretion (FENa), and significant decreases in RBF, GFR, UV, and urinary sodium excretion (UNaV).

The infusion of ANP reduced BP in both groups. The mean BP of the control rats was lower than that of the ARF rats throughout all the clearance periods, but it remained above the lower limit of renal autoregulation $(=100 \mathrm{mmHg})$ in this species. $\left.{ }^{12}\right) \quad$ In the control period, the GFR of the ARF rats was severely depressed to less than $5 \%$ of that of the control rats. Although ANP infusions increased the GFR in both groups, the absolute GFR increase in the ARF rats was smaller than that in the control rats (Group $1 ;+0.18 \pm 0.12 \mathrm{ml} / \mathrm{min}$, Group 2; $+0.51 \pm 0.25 \mathrm{ml} / \mathrm{min},<0.05)$. Despite a smaller GFR increase the diuretic and natriuretic responses to ANP did not differ between groups. It is suggested that renal tubular damage was responsible for the large increases in FENa in Group 1 during the control period, and was further increased by the ANP infusion.

Figure 1 shows typical RBF records. Shortly after the ANP infusion a transient RBF increase was observed in every rat from Group 2 (lower trace in Fig. 1), followed by a gradual decline below the control level. By contrast, the RBF of the ARF rats (Group 1) increased monotonically after the ANP infusion (upper graph in Fig. 1), reaching about $150 \%$ of the control value during the experimental period (Table I). An attempt to generate a time-control group for ARF rats was unsuccessful because pulmonary congestion forced the termination of the experiment before the recovery period. Saline infusions without ANP in 5 rats, though, did not affect any parameters during either the control or the experimental periods; GFR $(0.05 \pm 0.01$ vs $0.05 \pm 0.01 \mathrm{ml} / \mathrm{min}), \mathrm{UNaV}(0.13 \pm 0.03$ vs $0.15 \pm 0.03 \mu \mathrm{eq} / \mathrm{min}), \mathrm{RBF}(3.46 \pm$ 0.35 vs $3.46 \pm 0.43 \mathrm{ml} / \mathrm{min})$.

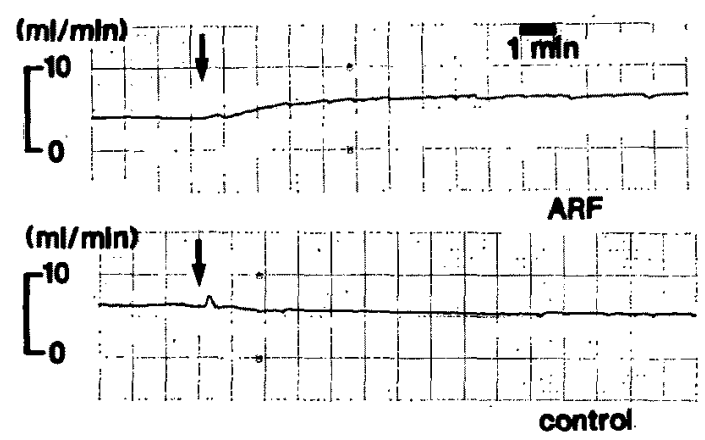

Fig. 1. Typical RBF responses to ANP in the ARF group (above) and the control group (below). Arrows indicate the beginning of ANP infusion. 


\section{Chronic experiments:}

The long-term effects of a 75-min ANP infusion on the course of ARF are summarized in Table II. Control values for BUN and plasma creatinine were comparable between Group 3 (saline-treated) and Group 4 (ANP-treated) (BUN $19.6 \pm 0.8 \mathrm{mg} / \mathrm{dl}$ in Group 3 and $18.2 \pm 0.4 \mathrm{mg} / \mathrm{dl}$ in Group 4, creatinine $0.35 \pm 0.03 \mathrm{mg} / \mathrm{dl}$ in Group 3 and $0.34 \pm 0.02 \mathrm{mg} / \mathrm{dl}$ in Group 4). Twenty-four hours after the glycerol injection these values increased in both groups, but the ANP infusion group showed a significantly lower degree of azotemia (BUN $89.8 \pm 8.5 \mathrm{mg} / \mathrm{dl}$ in Group 3 and $53.4 \pm 6.3 \mathrm{mg} / \mathrm{dl}$ in Group $4, \mathrm{p}<0.01)$ and a lower plasma creatinine level. There were no significant differences in $\mathrm{Ht}$ and water intake between these groups. Although we did not attempt to determine the exact water balance during the saline or ANP infusion, there were no significant differences in measured UV or $\mathrm{UNaV}$ between the 2 groups.

\section{Histologic studies:}

Histologic sections of 12 kidneys from each group in the chronic experiment were analyzed. In general, necrosis was most severe in the $S_{1}$ and the $\mathrm{S}_{2}$ segments of the proximal tubule, and less severe changes were observed in the $S_{3}$ segment of the proximal tubule. Cast formation was equally extensive in the outer and the inner medulla.

Table II. Long-Term Effects of ANP on the Course of ARF

\begin{tabular}{c|c|c|c|c|c|c}
\hline & $\begin{array}{c}\text { BUN } \\
(\mathrm{mg} / \mathrm{dl})\end{array}$ & $\begin{array}{c}\text { Creat } \\
(\mathrm{mg} / \mathrm{dl})\end{array}$ & $\begin{array}{c}\mathrm{Ht} \\
(\%)\end{array}$ & $\begin{array}{c}\mathrm{UV} \\
(\mathrm{ml} / \mathrm{day})\end{array}$ & $\begin{array}{c}\text { UNaV } \\
(\mathrm{meq} / \text { day })\end{array}$ & $\begin{array}{c}\text { Water Intake } \\
(\mathrm{ml} / \text { day })\end{array}$ \\
\hline Group 3 & & & & & & \\
Mean & 89.8 & 2.65 & 38.3 & 25.9 & 0.76 & 47.5 \\
SEM & 8.5 & 0.30 & 1.1 & 5.5 & 0.17 & 5.7 \\
Group 4 & & & & & & \\
Mean & $53.4^{*}$ & $1.63^{*}$ & 38.7 & 37.1 & 1.18 & 59.6 \\
SEM & 6.3 & 0.18 & 0.8 & 7.0 & 0.16 & 8.1 \\
\hline
\end{tabular}

Group 3: saline-treated rats $(\mathrm{N}=13)$, Group 4: ANP-treated rats $(\mathrm{N}=12)$. Creat=plasma creatinine. Data were obtained 24 hours after the glycerol injection. $* \mathrm{P}<0.01$ vs Group 3 .

Table III. Summary of the Histologic Data

\begin{tabular}{c|c|c}
\hline & $\begin{array}{c}\text { Median grade of } \\
\text { proximal necrosis }\end{array}$ & $\begin{array}{c}\text { Median grade of casts } \\
\text { in the outer medula }\end{array}$ \\
\hline Group 3 $(\mathrm{N}=12)$ & 3 & 3 \\
Group 4 $(\mathrm{N}=12)$ & 2 & 2 \\
$\mathrm{P}^{*}$ & $<0.05$ & $<0.10$ \\
\hline
\end{tabular}

* Comparison between Group 3 (saline-treated rats) and Group 4 (ANP-treated rats). 


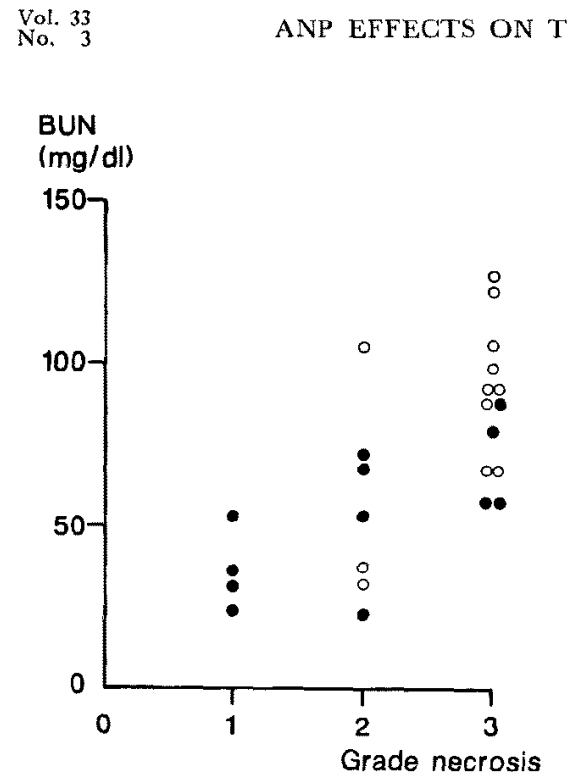

Fig. 2. Correlation between BUN and the degree of proximal necrosis $\left(r_{k}=0.057\right.$, $p<0.05)$. Open and closed circles represent Group 3 (saline-treated) and Group 4 (ANP. treated) rats, respectively.

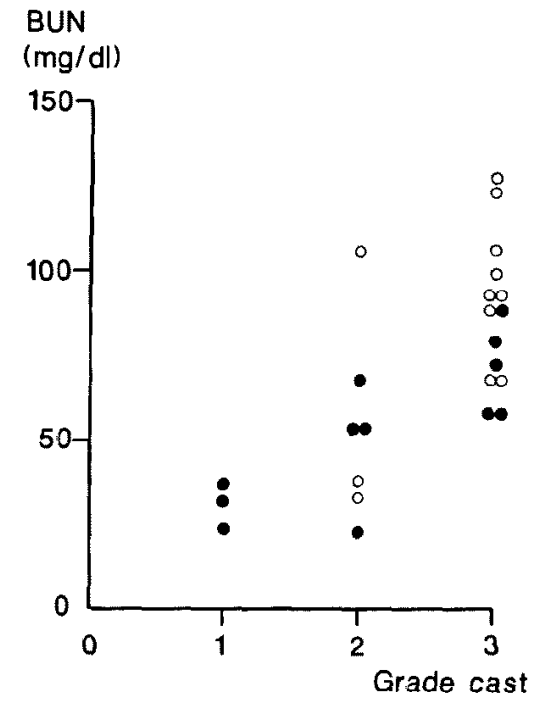

Fig. 3. Correlation between BUN and the extent of cast formation in the outer medulla $\left(\mathrm{r}_{\mathrm{k}}=0.593, \mathrm{p}<0.05\right)$. Open and closed circles represent Group 3 and Group 4 rats, respectively.

Table III summarizes the results of the histologic studies. The grade of necrosis in the proximal tubule was significantly lower in the ANP-treated rats (Group 4) than in the saline-treated rats (Group 3). The extent of cast formation in the outer medulla also tended to be less severe in Group 4, although this tendency was not statistically significant. Figure 2 illustrates the relationship between the severity of necrosis in the proximal tubule and BUN, and Fig. 3 the relationship between the extent of cast formation in the outer medulla and BUN. Moderately strong correlations existed in both cases (necrosis $\sim$ BUN; $\mathrm{r}_{\mathrm{k}}=0.557, \mathrm{p}<0.05$, cast $\sim \mathrm{BUN} ; \mathrm{r}_{\mathrm{k}}=0.593, \mathrm{p}<0.05$ ).

\section{Discussion}

The present study demonstrated a therapeutic effect of ANP during both acute renal dysfunction and the chronic course of glycerol-induced ARF.

In acute experiments, ANP induced a profound natriuresis in the ARF rats although the GFR increase by ANP was smaller than that in the control rats. In view of the small GFR response, this natriuresis may be due to either reduced tubular reabsorptive capacity (reflected by increased FENa) and/or direct tubular effects of ANP.13),14) These responses to ANP are consistent with the recent report by Heidbreder et al, ${ }^{15}$ which examined the 
acute effects of ANP in the less severe form of glycerol-induced ARF.

Several recent studies have shown that ANP can almost completely restore the GFR in the ischemic ARF model. ${ }^{6)-8)}$ The reasons for the lack of GFR restoration in the present study are unknown. However, differences between ischemic and glycerol models ${ }^{16)}$ may be responsible for this discrepancy. Detailed information about the altered renal microcirculation after the glycerol injection should help resolve this question.

The decreased RBF in the ARF rats is a common finding in the glycerol model ${ }^{2,171-19)}$ and filtration failure is generally attributed to cortical ischemia. ${ }^{17), 18}$ In addition to plasma volume depletion, activation of the reninangiotensin system is thought to be involved in the fall of RBF.11,19)-21) Interestingly, the RBF responses to ANP were quite different between the control and ARF rats: a sustained RBF increase was observed only in the ARF group. The slight decrease in RBF in the control group cannot be attributed to hypotension because $\mathrm{BP}$ remained within the limits for renal autoregulation. ${ }^{12}$ In this regard, Camargo et al reported that ANP decreased the renal vascular resistance in the presence of norepinephrine, angiotensin II (AII), or vasopressin, and increased the resistance in the absence of any vasoconstrictors. ${ }^{221}$ From these observations they concluded that ANP behaves as a functional agonist/antagonist of endogenous vasoconstrictors, which may explain the different patterns of RBF responses to ANP in the present study.

In chronic experiments, the 75-min ANP infusion after the glycerol injection significantly lessened the degree of both azotemia and renal histological injury. There are several possible mechanisms for these long-term protective effects of ANP.

First, the improvement of RBF during ANP infusion could partially protect the kidney from ischemic insult. However, a previous study showed that RBF improvement induced by the inhibition of AII did not improve the renal dysfunction in this model, ${ }^{21}$ ) suggesting that the beneficial effects of ANP cannot be completely explained by the improvement of RBF. Second, ANPinduced diuresis could prevent intratubular cast formation. Tubular obstruction by casts is not considered to be the most important factor for the reduced filtration in the early stage of the glycerol model.11,201,23) However, Cushner et al suggested that intratubular casts play some role in the maintenance stage of this model. ${ }^{24}$ The results of our histologic analysis seem to support this view. Similar to other reports, ${ }^{251,26)}$ the degree of proximal necrosis and the extent of cast formation in the outer medullar correlated well with the degree of azotemia. Both the degree of necrosis and cast formation tended to be less severe with ANP treatment, but only the effect on necrosis was statistically significant. The demonstration of these correlations does not neces- 
sarily mean a causal relationship, but these results suggest that the long-term effect of ANP may in part come from the prevention of the cast formation. Finally, other actions of ANP could protect the kidney against glycerol-induced ARF. The direct tubular effects of ANP (such as influences on intracellular calcium concentrations) should be clarified in future studies.

In addition to different effects on GFR (discussed previously), there is a discrepancy in histological findings from ischemic and glycerol-induced AFR. Specifically, ANP did not lessen the renal histological injuries in the ischemic model despite more favorable responses in the acute phase. ${ }^{7}$ We cannot readily explain this discrepancy. However, it is likely that the mechanisms of action of ANP are different in these different experimental models of ARF. In this regard, it is important to note that these models respond differently to other agents such as furosemide. ${ }^{1,2)}$

The results of the present study suggest that ANP may be useful in the treatment of human ARF. Although the protective effects of ANP have been documented previously in the ischemic ARF model, 6)-9) the glycerol model is thought to better reproduce some types of human ARF.101,11) The clinical use of ANP in ARF is of considerable interest. However, the prevention of severe hypotension during ANP infusion will be critical. We needed to replenish large volume losses during the ANP-induced natriuresis to avoid systemic hypotension. Given the unstable hemodynamic status of many ARF patients, the combined use of vasoactive agents such as dopamine with ANP may be worth considering in clinical trials, as suggested by Conger et al. ${ }^{9}$

In summary, ANP induced a profound natriuresis and improved both GFR and RBF in the early stages of the glycerol-induced ARF model. However, the improvement of GFR was smaller compared to the previous results in the ischemic model. An ANP infusion after a glycerol injection also lessened both the degree of azotemia and the extent of the renal histologic injuries. These results are more promising than the effects of furosemide previously reported in this model, ${ }^{1), 2}$ suggesting that ANP may be useful in the treatment of ARF.

\section{ACKNOWLEDGMENTS}

Portions of the present study were presented at the 10th International Congress of Nephrology, London, UK, July 1987.

The authors thank Miss A. Arai and Mrs. K. Naiki for their skillful technical assistance, and Mr. Y. Fukuda for help with the statistical analysis. 


\section{REFERENCES}

1. Baily PR, Natale R, Turnbull DI, Linton AL: Protective effect of furosemide in acute tubular necrosis and acute renal failure. Clin Sci Molec Med 45: 1, 1973

2. Greven J, Klein H: Renal effect of furosemide in glycerol induced acute renal failure of the rat. Pflügers Arch 365: 81, 1976

3. Epstein M, Schneider NS, Befeler B: Effect of intrarenal furosemide on renal function and intrarenal hemodynamics in acute renal failure. Am J Med 58: 510, 1975

4. De Torrente A, Willer PD, Cronin RE, Paulsen PE, Erickson AL, Schrier RW: Effect of furosemide and acetylcholine in norepinephrine-induced acute renal failure. Am $\mathrm{J}$ Physiol 235: F131, 1978

5. Linder A, Cutler RE, Goodman WG, Pansing PA, Kuester R: Synergism of dopamine plus furosemide in preventing acute renal failure in the dog. Kidney Int 19:158, 1979

6. Schafferhans K, Heidbreder E, Grimm D, Heidland A: Norepinephrine-induced acute renal failure: beneficial effects of atrial natriuretic factor. Nephron 44: 240, 1986

7. Nakamoto M, Shapiro JL, Shanley PF, Chan L, Schrier RW: In vitro and in vivo protective effect of atriopeptin III on ischemic acute renal failure. J Clin Invest 80:698, 1987

8. Shaw SG, Weidmann P, Hodler J, Zimmermann A, Paternostro A: Atrial natriuretic peptide protects against acute ischemic renal failure in the rat. J Clin Invest 80: 1232, 1987

9. Conger JD, Falk SA, Yuan BH, Schrier RW: Atrial natriuretic peptide and dopamine in a rat model of ischemic acute renal failure. Kidney Int 35: 1126, 1989

10. Finck ES: Experimental acute tubular nephrosis following subcutaneous injection of glycerol. J Path Bac 73: 69, 1957

11. Oken DE, Arce ML, Wilson DR: Glycerol-induced hemoglobinuric acute renal failure in the rat. I. Micropuncture study of the development of oliguria. J Clin Invest 45: 724, 1966

12. Chevalier RL, Kaiser DL: Autoregulation of renal blood flow in the rat: effects of growth and uninephrectomy. Am J Physiol 244: F483, 1983

13. Nonoguchi H, Sands JM, Knepper MA: Atrial natriuretic factor inhibits vasopressin-stimulated osmotic water permeability in rat inner medullary collecting duct. J Clin Invest 82: 1383,1988

14. Nonoguchi H, Sands JM, Knepper MA: ANF inhibits NaGl and fluid absorption in cortical collecting duct of rat kidney. Am J Physiol 25: F179, 1989

15. Heidbreder E, Schafferhans K, Schramm D, Gotz R, Heidland A: Toxic renal failure in the rat: beneficial effects of atrial natriuretic factor. Klinische Wochenschrift 64 (suppl VI): 78, 1986

16. Brenner BW, Lazarus JM: Acute Renal Failure, WB Saunders, Philadelphia, p 105, 1983

17. Ayer G, Grandchamp A, Wylcr T, Truniger B: Intrarenal hemodynamics in glycerol-induced acute renal failure in the rat. Circ Res 29: 128, 1971

18. Chdru MF, Baethke R, Oken DE: Renal cortical blood flow and glomerular filtration in myohemoglobinuric acute renal failure. Kidney Int 1: 232, 1972

19. Hsu CH, Kurtz TW, Waldinger TP: Cardiac output and renal blood flow in glycerol-induced acute renal failure in the rat. Circ Res 40:178, 1977

20. Thiel G, McDonald FD, Oken DE: Micropuncture studies of the basis for protection of renin depleted rats from glycerol induced acute renal failure. Nephron 7: 67, 1970

21. Ishikawa I, Hollenberg NK: Pharmacological interruption of the renin-angiotensin system in myohemoglobinuric acute renal failure. Kidncy Int 10: S183, 1976

22. Camargo MJF, Kleinert HD, Atlas SA, Sealey JE, Laragh JH, Maack T: Ca-dependent hemodynamic and natriuretic effects of atrial extract in isolated rat kidney. Am J Physiol 246: F447, 1984

23. Ruiz-Guinau A, Coclho JB, Paz RA: Methemoglobin-induced acute renal failure in the rat. In vivo observation, histology and micropuncture measurements of intratubular and post- 
glomerular vascular pressures. Nephron 4: 257, 1967

24. Cushner HM, Barnes JL, Stein JH, Reineck HJ: Role of volume depletion in the glycerol model of acute renal failure. Am J Physiol 250: F315, 1986

25. Solez K, Morel-Maroger L, Sraer JD: The morphology of " acute tubular necrosis" in man: analysis of 57 renal biopsies and a comparison with the glycerol model. Medicine 58: 362, 1979

26. Richards GJ, DiBona GF: Acute renal failure: structural-functional correlation. Proc Soc Exp Med 146: 880, 1974 